\title{
Aproximações e distanciamentos da carreira docente em Química com sujeitos da Argentina e do Brasil
}

Cíntia de Abreu Arruda* (Graduanda da Lic. em Química do Instituto Federal de Educação, Ciência e Tecnologia de Pernambuco - Campus Vitória)

Maria Tatiana da Silva Santos (Graduanda da Lic. em Química do Instituto Federal de Educação, Ciência e Tecnologia de Pernambuco - Campus Vitória)

Rhaylene de Almeida Ramos (Graduanda da Lic. em Química do Instituto Federal de Educação, Ciência e Tecnologia de Pernambuco - Campus Vitória)

Kilma da Silva Lima Viana (Professora Dra do Curso de Licencitura em Química, Líder do Grupo de Pesquisa - GEPEC e Coordenadora do Geral do PDVL, do Instituto Federal de Educação, Ciência e

Tecnologia de Pernambuco - Campus Vitória)

*Email: cintiaarruda@outlook.com

resumo:

Este artigo teve o objetivo de compreender as condições de trabalho dos professores de Química de uma escola do Brasil e da Argentina e suas relações com a escolha e não escolha dos estudantes pela carreira docente nessa área. Foi desenvolvido com quatro (4) professores e quarenta e três alunos (43) de duas escolas, uma situada na cidade de Vitória de Santo Antão em Pernambuco, Brasil, o Instituto Federal de Educação, Ciência e Tecnologia e outra na Argentina no Colégio Nacional de La Plata. Os professores de ambas as escolas afirmaram que não são totalmente satisfeitos com a profissão, e apontaram como principais razões: grande demanda de conteúdo em uma carga horária reduzida, o desenvolvimento do conhecimento, a atitude e o compromisso com a escola, a falta de desenvolvimento de teorias pedagógicas, e além de tudo, a desvalorização social. Os estudantes entrevistados não pensam em seguir a carreira docente em Química porque afirmam que essa ciência é de difícil compreensão, além de relatarem que a profissão docente possui baixos salários, fazendo com que os mesmos optem por áreas como medicina e direito por ser mais bem remuneradas. Por tanto, com os resultados obtidos observamos que existem mais aspectos que se aproximam do que aqueles que se distanciam em relação à carreira docente em Química nas escolas pesquisadas de ambos os países (Brasil e Argentina). Dos aspectos que se aproximam estão: as condições de trabalho, motivação profissional, percepções dos estudantes acerca da carreira docente, e, além disso, as dificuldades no processo de ensino-aprendizagem da Química. Já dentre os aspectos que se distanciam está a formação dos professores, uma vez que, na Argentina, os docentes não precisam ser formados especificamente em licenciatura para atuar em sala de aula, já em algumas escolas do Brasil, como as da rede federal de ensino, o professor só pode lecionar se possuir formação em licenciatura.

pallavras-chave:

Carreira docente; Condições de trabalho; Ensino-aprendizagem em Química; 


\section{I ntrodução}

A América Latina apresenta similitudes e particularidades marcantes no conjunto de seus países no que se refere ao âmbito social, político e econômico, o que impõe certos cuidados na análise das experiências recentes no campo educativo na região (OLIVEIRA; MELO, 2010).

A LDB tem proporcionado muitos debates sobre o futuro da educação, pois consideram que a educação é o único meio para a solução dos problemas sociais.

Concordando com (VIANA e CESAR; 2010), que a instrução se constitui em instrumento essencial e determinante para a capacitação ao trabalho e para a formação da consciência cidadã nas comunidades humanas.

Destacaremos neste trabalho a formação de profissionais na área da educação no Brasil e na Argentina e em especial, aos professores, sujeitos essenciais e que verdadeiramente estão juntos dos estudantes, dividindo não só a sala de aula, mas seus conhecimentos e experiências para os mesmos, contribuindo assim para a formação deles, em todos os aspectos, cognitivos, éticos e de cidadania (FUHR, 2010).

Dentre os professores, iremos focar nos licenciados em Química e aqueles que mesmo sem serem graduados na área, mas que lecionam nas escolas de ensino básico, no nível polimodal do $1^{\circ}$ ao $3^{\circ}$ Ciclo como é conhecido na Argentina e o Ensino Médio no Brasil do $1^{\circ}$ ao $3^{\circ}$ ano.

A carreira docente tanto no Brasil como na Argentina, vêm apresentando as mesmas possibilidades e desafios no que se refere as precárias condições de trabalho, a evasão de professores principalmente em escolas do ensino básico, e em alguns casos a má formação desses profissionais. O que torna a aprendizagem dos estudantes escassa em muitos casos, pois uma das possibilidades de uma boa aprendizagem está dependente da qualidade do ensino (MEZZADRA, VELEDA E SÁNCHEZ, 2014).

Segundo Carvalho (1995), o processo de constituição da identidade profissional vem sofrendo intensas transformações, decorrentes da assimilação de informações, conceitos e valores relativos às mudanças do mundo do trabalho e da influência da nova ordem social vigente.

À medida que o sujeito vai amadurecendo, surge a necessidade de assumir responsabilidades, ocupando assim, encargos trabalhistas na sociedade, e esse fato contribui tanto para o seu sustento quanto para o progresso do país.

A importância da educação na determinação do desenvolvimento, produtividade e desigualdade de renda nas nações é tema constante na literatura econômica (BARTALOTTI; FILHO, 2007).

Dessa forma, a escolha profissional é uma tarefa de grande importância para os seres humanos, porém nem sempre simples, pois os estudantes não precisam decidir apenas qual Universidade frequentar, mas também a carreira que pretende cursar.

Em relação aos profissionais da educação, Sales e Chamon (2011) afirmam que têm gerado muitas inquietações, principalmente sobre as responsabilidades atribuídas ao educador, questões salariais e condições de trabalho.

De acordo com as condições de trabalho docente no Brasil, Oliveira e Melo (2010), destacam que:

Diante das fortes pressões sofridas e dos sucessivos e permanentes limites, os docentes manifestam desgaste, desmotivação e, muitas vezes, desistência do magistério. À atuação restrita dos professores e à sua desvalorização, expressa em especial nos reduzidos salários, acrescenta-se algo que se atribui ao “desinteresse dos estudantes" como forte concorrente no processo de desmotivação docente.

A relação das condições de trabalho vivenciadas na Argentina em relação a carreira docente, é muito semelhante ao Brasil, apresentando as seguintes características, "instabilidade salarial, os espaços, tempos e recursos nem sempre adequados, e as problemáticas frente a difícil situação social de alguns contextos” (MEZZADRA, VELEDA E SÁNCHEZ, 2014). 
Para Ens, Eyng, Gisie e Ribas (2014), a busca pela profissão e permanência nela vêm se constituindo numa problemática histórica, motivo pelo qual é foco das preocupações das políticas educacionais nos últimos anos diante da constatação da enorme falta de profissionais licenciados e da diminuição crescente de matrículas em cursos de licenciaturas.

Através de pesquisas desenvolvidas na Argentina, observou-se que os estudantes optam pela docência, não por desejo, mas por que em muitos casos é a única alternativa de formação superior em sua localidade, porque é mais breve e menos exigente que outras carreiras universitárias e porque é seguro a perspectiva de emprego. (FANTANI et al, 2010 apud MEZZADRA, VELEDA E SÁNCHEZ, 2014).

Não é diferente no Brasil, pois a maioria dos estudantes que cursam licenciatura, não a tinha como primeira opção, mas sim outras áreas com melhor remuneração, como, medicina, direito ou engenharias, porém, os cursos dessas áreas requerem mais investimentos financeiros e os estudantes, geralmente, não tem condições para se manterem, e as Universidades públicas que oferecem esses cursos exigem um nível avançado nas avaliações em vestibulares para que os mesmos possam ingressar, o que leva esses estudantes optarem pelos cursos de Licenciatura, não por vontade, mas, sim, por julgarem mais “fácil” ingressar, já que não é muito concorrido (REIS, OLIVEIRA E KIOURANIS, 2013).

Estudos internacionais revelam que as maiores carências, frequentemente, apresentadas no ciclo superior do nível secundário, ou no caso do Brasil, ensino médio, são em ciências da natureza e exatas ou inglês e línguas nativas (UNESCO, 2012).

Por esse motivo, esta presente pesquisa, traz como abordagem principal a área de ciências naturais e exatas, com específico na disciplina de Química, devido ao grande índice de evasão de professores formados nas escolas em ambos os países.

Segundo dados encontrados na Sinopse Estatística do Professor (Brasil/Mec/Inep, 2014), o número de professores de Ciências e Matemática na Educação Básica, com formação superior, atuando em 2014, segundo a área de formação, era: Química (19.289); Física (15.240); Ciências (53.596); Ciências Biológicas (55.356); e Matemática (104.004).

Para Sá e Santos (2011), a diferença de profissionais formados em Ciências e Ciências Biológicas em relação aos profissionais formados em Química, apesar da pequena diferença no número de cursos de formação. Talvez, seja pelo fato que os cursos de Ciências e de Ciências Biológicas sejam mais atrativos por serem identificados com os cursos da área da Saúde, mais prestigiados socialmente, e formem um maior contingente de profissionais que vão para a EB.

Isso se acarreta, devido ao fato de serem reproduzidas nas escolas de Ensino Médio, práticas que não têm auxiliado nem na compreensão de conceitos dessa área, nem no despertar do interesse para a carreira docente (ANDRADE; SALES; LIMA, 2013).

Conforme com Sá e Santos (2011)

Há várias hipóteses para esse número pequeno de professores com formação em Química na escola básica, uma delas pode ser a falta de interesse desses profissionais pelo magistério após a conclusão de seu curso. Outra é que talvez os professores de Química da EB pratiquem um ensino pautado na reprodução de conteúdos cognitivos e processos avaliativos que não valorizam a construção do conhecimento, desestimulando o seu estudo pelos jovens. Destaca-se nos dados da Sinopse o fato de o número de formados em Matemática ser tão superior ao das demais áreas. Será que esse profissional considera que seu campo de atuação natural seja o ensino, uma vez que a pesquisa na área é mais restrita? Ou será que ele sabe estimular mais seus estudantes para a área? Podemos ainda especular que o estudante tome contato mais cedo na escolarização com a Matemática (e a Biologia) do que com a Química (e a Física) e tem, assim, mais tempo para desenvolver afinidade por aqueles conhecimentos.

Essa realidade acaba por afastar o desejo dos estudantes de ingressarem para o ensino de Química. Diante disso, faz-se necessário que seja repensada a formação do professor (incluindo 
estudos mais aprofundados sobre práticas inovadoras de ensino e de avaliação), para que seja possível formar professores que atuem no Ensino Médio de forma mais qualificada, tendo como base as novas perspectivas de ensino e de avaliação (SILVA et al, 2014).

Diante desse contexto, os estudantes que estão prestes a fazer uma escolha profissional, não escolhem seguir a profissão de professor para o seu futuro, pois consideram que existem outras áreas com condições mais satisfatória para crescerem profissionalmente, com isso, a educação em ambos os países se torna fragilizada (Maldaner, 2001).

Sendo assim, o trabalho tem como objetivo, compreender as condições de trabalho dos professores de Química de uma escola do Brasil e da Argentina e suas relações com a escolha e não escolha dos estudantes pela carreira docente nessa área.

Esse estudo comparativo entre esses dois países, é de suma importância, para fazermos buscar resultados comuns entre realidades distintas, também nos faz reconhecer as especificidades entre os países com os desafios presente na carreira docente.

\section{Metodologia}

Esse presente trabalho apresentou uma abordagem qualitativa, com o objetivo de compreender as condições de trabalho dos professores de Química de uma escola do Brasil e da Argentina e suas relações com a escolha e não escolha dos estudantes pela carreira docente nessa área.

a. Caracterização do campo da pesquisa

A pesquisa abrangeu duas escolas da Rede Pública, o Instituto Federal de Educação, Ciência e Tecnologia (Escola 1), localizado na cidade de Vitória de Santo Antão em Pernambuco, Brasil e o Colégio Nacional de La Plata (Escola 2), localizado na cidade de La Plata, na Província de Buenos Aires, Argentina.

\section{b. Sujeitos da Pesquisa}

Os sujeitos desta pesquisa foram dois $(n=2)$ professores de Química e trinta $(n=30)$ estudantes do Ensino Médio do Brasil da Escola 1 e dois $(\mathrm{n}=2)$ professores de Química e vinte e três $(n=23)$ estudantes do ensino terciário como é chamado aqui na Argentina da Escola 2.

c. Instrumentos de coleta

Para coleta de dados, foram utilizados questionários que, em suma, buscavam compreender as concepções dos professores acerca da carreira docente, abordando os desafios e os obstáculos enfrentados no decorrer do trabalho e identificar as principais dificuldades dos estudantes no processo de aprendizagem em Química e sua relação com o despertar para a carreira docente nessa área.

Aos estudantes foram também aplicados questionários com a perspectiva de identificar suas percepções para a carreira docente, com foco em Química e o desenrolar da sua aprendizagem na área, se de alguma forma, isso contribui para a sua escolha ou não escolha em seguir essa carreira profissional.

\section{Questionário dos professores}

1- Qual a sua formação?

2- Você é satisfeito com essa profissão?

3- As condições de trabalho são satisfatórias?

4- Quais as dificuldades enfrentadas no decorrer do trabalho?

5- Você incentiva seus alunos a seguir a profissão docente? Por quê?

\section{Questionário dos alunos}


1. Qual a escolha profissional você pensa para o seu futuro?

2. O que você acha da profissão de professor?

3. Você tem vontade de ser professor? ( ) Tenho muita vontade ( ) Tenho pouca vontade ( ) Não tenho vontade

4. Você é incentivado a ser professor?

( ) Sou muito incentivado ( ) Sou pouco incentivado ( ) Não sou incentivado

5. Com relação aos conteúdos de Química, você: ( ) Aprende com Facilidade ( ) Aprende com Dificuldade ( ) Não aprende

6. Se você "não aprende” ou "aprende com dificuldade” os conteúdos de Química, marque as alternativas que indicam os principais motivos.

( ) Tenho dificuldade com Matemática ( ) Tenho dificuldade em decorar muitas fórmulas ( ) Tenho dificuldade de entender as aulas do professor ( ) Tenho dificuldade com as aulas experimentais ( ) Tenho dificuldade em entender as questões das provas ( ) Tenho outra dificuldade. Qual?

7 - Você costuma possuir um bom desempenho nas avaliações de Química?

\section{Resultados e Discussões}

\section{- Professores}

A partir da aplicação dos questionários, tanto aos docentes quantos aos estudantes do Brasil e Argentina, observamos que há aproximações e distanciamentos em relação ao sistema educativo e a percepção dos estudantes sobre a carreira docente.

No Brasil, todos os professores de ensino médio são formados em Licenciaturas, porém, na maioria das vezes, os professores que lecionam a Química, não possuem formação específica na área, mas sim, em outras, o que faz com que professores com outras formações atuem nas salas de aula de química sem o total domínio dos conteúdos. De acordo com (Silva, 2011), no início de 2010, o Censo da Educação Superior mostra que o Brasil forma cada vez menos professores, sendo em Química uma das maiores quedas (-7\%) de 2006 para 2007, o que justifica o feito citado acima. Contudo, um dos campos dessa pesquisa foi uma instituição Federal de ensino do Brasil, onde o docente só pode lecionar na área que possuir sua devida formação.

Na Argentina, os docentes não precisam ser formados especificamente em licenciatura para atuar em sala de aula, no caso da Química, os mesmos podem possuir outras carreiras, como: medicina, farmácia, engenharia, entre outras áreas que tenham alguma relação com a disciplina. Com isso, assim como em algumas escolas do Brasil, esse fato compromete a aprendizagem dos estudantes, pois, o professor que não possui a formação específica na área em que atua, não possui o domínio necessário e total segurança para promover o conhecimento.

Tanto os professores da Escola 1, assim como os da Escola 2, apesar de trabalharem em instituições de destaque no país, com boa estrutura física, com laboratórios de Química bem equipados e salas de aula em boa qualidade, relataram que não são totalmente satisfeitos com a profissão, pois um dos principais problemas relatados por ambos foi a imensa quantidade de conteúdos que precisam ser abordados em uma carga horária reduzida, fazendo com que os mesmos corram contra o tempo se preocupando mais em atender a demanda de conteúdos do que garantir a aprendizagem dessa ciência, principalmente nos anos que antecedem o vestibular. Diante desse cenário, o professor acaba apenas repassando os conteúdos, muitas vezes, reproduzindo o livro didático, passando os conteúdos de forma superficial sem fazer as devidas relações com o cotidiano do aluno, tornando assim, as aulas de Química repetitivas, sem contextualização e de pouco interesse para os estudantes, que por consequência, não se sentem atraídos em ingressar nessa área do conhecimento.

Demais dificuldades apresentadas pelos professores da Escola 1 e da Escola 2, foram: o desenvolvimento do conhecimento, a atitude e o compromisso com a escola, a falta de desenvolvimento de teorias pedagógicas, e a além de tudo, a desvalorização social.

Diante desse contexto, os mesmos sentem-se cansados e desmotivados com a realização profissional. Segundo Silva (2012) “A desmotivação dos professores vem desde os baixos 
salários, o desinteresse dos estudantes, a falta de estrutura, até a falta de interesse dos pais dos estudantes e a sociedade que transferiram algumas de suas responsabilidades para a escolha. " Com isso, a carreira docente torna-se cada vez menos atrativa e prestigiada socialmente, fazendo com que falte professores qualificados para o exercício da profissão.

Para Mezzadra, Veleda e Sánchez (2014), é necessário reconhecer que são diversas as problemáticas que apresenta esta profissão na atualidade, entre elas: uma oferta de formação inicial que dá conta de certas fragmentações; um sistema de distribuição de docentes que nem sempre responde a critérios de equidade; a escassez de incentivos, condições de trabalho e mecanismos de promoção que contribuam a oferecer condições de trabalhos estimulantes; entre outras.

Com a pesquisa, buscamos saber também se apesar das dificuldades que apresenta essa profissão, os professores incentivavam os seus estudantes a seguirem a carreira docente. Os professores da Escola 2 abordaram incentivar os estudantes a seguirem a profissão de professor, pois afirmam que é uma área de formação contínua e de grande importância para o conhecimento das novas gerações. Para eles, é uma profissão desafiante a cada dia.

O Instituto Federal de Pernambuco desenvolve um programa denominado Programa Internacional Despertando Vocações para Licenciatura (PDVL), em parceria com os Institutos Federais de Alagoas, Paraíba, Sertão Pernambucano, Rondônia, Piauí e Goiás e com a Universidad Nacional de La Plata e Universidad de Mendoza (ambas na Argentina), a Universidad de Playa Ancha (no Chile) e o Ministério da Educação do Panamá (MEDUCA Panamá), que vai nessa direção, pois tem o objetivo de despertar o interesse de estudantes do Ensino Médio para a carreira docente, entretanto, observa-se o grande esforço que deve ser realizado pelo PDVL para superar a realidade dessa carreira no Brasil, principalmente em Química onde há uma grande evasão.

\section{- Estudantes}

Com o estudo, investigamos quais eram as principais escolhas profissionais para o futuro dos estudantes, quais eram suas concepções sobre a carreira docente e quais as suas principais dificuldades em aprender a Química, se esta disciplina despertava o gosto dos mesmos para seguir essa área ou não.

A maioria dos estudantes da Escola 1, pensa em seguir carreira profissional em áreas como Medicina, Engenharia e Direito, já os da Escola 2, além dessas duas profissões, apontaram também Jornalismo como uma futura escolha. Ambos os grupos de estudantes alegaram que tais profissões são mais reconhecidas, e que o salário compensa o trabalho que é realizado. Nesse sentido, podemos notar que existem aproximações entre as escolhas para o futuro profissional por parte dos estudantes entrevistados, sendo as áreas de licenciaturas as de menor interesse. Destacamos também, que, a questão salarial e o reconhecimento social são pontos fortes para os jovens quando se pensa em optar por uma carreira profissional. Logo, os jovens pensam em seguir carreiras que sejam mais valorizadas, com bons salários e boas condições para o trabalho.

Foi perguntado o que os estudantes achavam da profissão de professor. Destacamos aqui algumas respostas:

"É muito importante a profissão do professor, afinal, todos os profissionais passaram pelos professores".

"Acho muito importante, pois ajuda os estudantes a terem um futuro melhor".

"Pena que é pouco privilegiada".

"No me gusta, pero tiene una importância em la sociedad y estan mal pagados. "

"Pienso que es buena y sirve em el desarollo del país."

"Me gusta, pero no estoy de acuerdo com el sueldo que obtienen, es bajo".

Nas respostas atribuídas pelos estudantes, podemos observar que os mesmos reconhecem a importância do ser docente na sociedade, seja ele como partícipe do processo educativo, sendo um facilitador do conhecimento que é levado para toda vida, ou seja, um ser capaz de transformar vidas. Porém, devido ao contexto que o professor está inserido nos dias atuais, diante de uma profissão que exige muito esforço, dedicação e tempo, e com salários 
baixos que não compensam sua jornada de trabalho, os estudantes não são incentivados a seguir a carreira docente, nem se sentem atraídos em ingressar nessa área. Essa realidade faz com que sobrem vagas nos cursos de licenciaturas, e faltem professores, inclusive de Química.

Em relação à aprendizagem de Química a maioria dos estudantes, tanto da Escola 1 quanto da Escola 2, aprendem os conteúdos com dificuldade e nem sempre se dão bem nas avaliações. As principais dificuldades apontadas pelos estudantes em compreender a Química, foram: Memorização de fórmulas, conceitos e regras matemáticas; interpretação das questões das provas, e dificuldades em compreender as aulas do professor, pois, muitos docentes não conseguem relacionar os assuntos químicos com o cotidiano. Podemos observar isso na fala de um aluno da Escola 2 que diz: "No me gusta porque no son temas que se relacionen com mi vida cotidiana." Esse fato faz com que os estudantes julguem a Química uma matéria de pouca aplicabilidade, que se resume apenas a fórmulas e conceitos que servem apenas para serem memorizados e reproduzidos na avaliação.

Se focarmos nosso olhar para as relações entre a avaliação e o despertar para a carreira docente, é possível observar que dentre as principais está a dificuldades com as provas. Se ainda olharmos para o seguinte aspecto: decorar fórmulas, é possível verificar que, possivelmente, essa resposta está diretamente ligada a outra, pois no cotidiano das aulas não há necessidade de se decorar fórmulas, os estudantes podem a qualquer momento olhar o caderno, verificar nos livros, etc. Porém, no momento da prova, para a grande maioria dos professores que apresentam abordagens tradicionais, é essencial decorar as fórmulas

Algumas pesquisas têm mostrado que as práticas presentes nas salas de aula de Química geralmente exigem que os estudantes memorizem fórmulas, conceitos, e regras matemáticas, fazendo com que os estudantes não se apropriem e dominem os conteúdos químicos, ficando limitado apenas por memorizar aquilo que convém para realizar as provas, sem ao menos entender a importância do que está estudando. A exigência de memorização é tanta que muitas vezes os estudantes são prejudicados, pois mesmo sabendo resolver todas as questões, caso esqueçam as fórmulas, não conseguem boas notas. Como o ensino da Química, historicamente, sempre esteve atrelado com práticas relacionadas à memorização, reprodução e fixação (Lima, 2008) os estudantes que têm dificuldade com essa abordagem ficam à margem do processo e a consequência disso é o desinteresse pela área.

Segundo Torricelli (2007) um ensino centrado no uso de fórmulas e cálculos, memorização excessiva contribuem para o surgimento de dificuldades de aprendizagem e desmotivação dos estudantes.

Portanto, podemos relacionar a não atratividade da carreira docente em Química com as dificuldades que os estudantes sentem, visto que, os mesmos não optam muitas vezes por essa área porque afirmam que é uma ciência de difícil compreensão, pois não entendem a importância de estudar os fenômenos químicos e tampouco a relação dos mesmos com o mundo em que vive, também pelo fato de não tirarem uma boa nota nas avaliações, logo, não vão querer seguir uma área em que não possuem um bom desempenho.

\section{Conclusões}

Diante do exposto, podemos concluir que existem mais aspectos que se aproximam do que aqueles que se distanciam em relação à carreira docente em Química nas escolas pesquisadas de ambos os países (Brasil e Argentina), no que se refere às condições de trabalho, motivação profissional, percepções dos estudantes acerca da carreira docente, e, além disso, as dificuldades no processo de ensino-aprendizagem da Química.

Nessa pesquisa, verificamos que há vários fatores relacionados ao não interesse em seguir a carreira docente em Química, sendo as condições de trabalho docente na atualidade uma das principais razões. Outro fator também que acarreta na não escola pela área é a avaliação, visto que, muitos estudantes não optam por um curso de licenciatura em Química porque sentem dificuldades em entender as aulas dos professores, em memorizar fórmulas e isso consequentemente acarreta em um baixo desempenho nas avaliações.

A escolha pela carreira docente é algo que deve ser estimulada nas escolas, e, principalmente, diante de uma crise tão grande que a área de formação de professores está 
vivendo nos últimos anos, com a baixa procura e precarização do fazer docente, sendo comum encontrar pessoas não habilitadas a exercerem a função de professor. Observamos a partir do GEPEC (Grupo de Estudos e Pesquisas em Ensino de Ciências) que nas escolas do Brasil há professores de diversas áreas ministrando a disciplina, entre eles, professores de Biologia, de Matemática, de Física e até de Português e História, o que faz com que eles não possuam o desempenho necessário para o ensino dessa ciência e no caso da Argentina, os professores de Química geralmente não possuem formação na área da docência, mas sim em áreas como engenharia, farmácia e outras que se relacionam com a Química, porém não possuem a didática necessária para transmitir e facilitar a compreensão dos conhecimentos químicos.

Diante desse contexto, muito ainda precisa ser feito. Criar novos métodos de ensino e programas que despertem o interesse dos estudantes em seguir essa área é um dos caminhos, já que, no Brasil e na Argentina, essa temática ainda é rudimentar, pois, a procura pelos cursos de licenciaturas está cada vez menor, fazendo com que sobrem vagas nos cursos de formação de professores. Ressalta-se assim, a importância de tornamos as aulas de Química mais atrativas, interessantes e, sobretudo, que possibilitem o envolvimento do estudante no processo de ensino aprendizagem.

\section{Agradecimentos}

Primeiramente agradeço a Deus, ao Grupo de Estudos e Pesquisas em Ensino de Ciências - GEPEC e ao Programa Internacional Despertando Vocações para Licenciaturas - PDVL, o qual sou integrante, a minha orientadora professora Kilma Viana e ao Instituto Federal de Educação, Ciência e Tecnologia de Pernambuco Campus Vitória de Santo Antão pelo suporte para a realização da presente pesquisa.

\section{Similarities and differences of the teaching profession in Chemistry with subjects of Argentina and Brazil}

\section{Abstract:}

This article aims to understand the working conditions of Chemistry teachers of a school in Brazil and Argentina and its relations with the choice and not the choice of students for teaching careers in this area. It was developed with four (4) teachers and forty-three students (43) of two schools, one in the city of Vitória de Santo Antão in Pernambuco, Brazil, the Federal Institute of Education, Science and Technology and another in Argentina at the National College La Plata. Teachers from both schools said they are not fully satisfied with the profession, and pointed out as main reasons: high demand for content on a reduced workload, the development of knowledge, attitude and commitment to the school, the lack of development pedagogical theories, and above all, the social devaluation. Respondents students do not think about following a teaching career in chemistry because they claim that science is difficult to understand, and report that the teaching profession has low wages, making them opt for areas such as medicine and law to be better paid. Therefore, with the results we observe that there are aspects that are close to those who are distant in relation to teaching career in chemistry in schools surveyed in both countries (Brazil and Argentina). Aspects of that approach are: working conditions, professional motivation, perceptions of students about the teaching profession, and also the difficulties in the teaching of chemistry process. But among the aspects that move away is the training of teachers, since, in Argentina, teachers do not need to be specifically trained in degree to work in the classroom, as in some schools in Brazil, such as the federal school system the teacher can only teach if you have training in degree. 


\section{Referências Bibliográficas}

ANDRADE, R. S.; SALES, E. S.; LIMA, K. S. A avaliação no ensino da química: um estudo com professores em formação. In: $3^{\circ}$ Congresso Internacional de Avaliação, 2013, Gramado. Anais do Congresso Internacional de Avaliação, 2013.

BARTALOTTI, O.; FILHO, N. M. A Relação entre o Desempenho da Carreira no Mercado de Trabalho e a Escolha Profissional dos Jovens. Econ. Aplic., São Paulo, V. 11, N. 4, P. 487-505, OUTUBRO-DEZEMBRO, ANO 2007.

BRASIL. Lei n ${ }^{\circ}$ 9.394, de 20 de dezembro de 1996. Estabelece as Diretrizes e Bases da Educação Nacional. Diário Oficial da República Federativa do Brasil, Brasília, v. 134, n. 248, 23 dez. 1996. Seção 1, p. 27834-27841.

BRASIL. Ministério da Educação/Inep. Sinopse do Censo da Educação Superior de 2014. Disponível em: <http://portal.inep.gov.br/basica-censo-escolar-sinopse-sinopse> Acesso: 24/09/2015.

CARVALHO, M.M.M.J. Orientação Profissional em Grupo: Teoria e Técnica. São Paulo: Editorial Psy, 1995.

ENSI, R. T.; EYNG, A. M.; GISI, M. L.; RIBAS, M. S. Evasão ou permanência na profissão: políticas educacionais e representações sociais de professores. Rev. Diálogo Educ., v. 14, n, 42, p. 501-523, Curitiba, maio/ago, 2014.

FUHR, L. M. O processo relacional entre o professor e o aluno. Monografia de Conclusão do Curso de Licenciatura em Pedagogia da Faculdade de Educação da Universidade Federal do Rio Grande do Sul - FACED/UFRGS, Porto Alegre, 2010.

LIMA, K. S. Compreendendo as Concepções de Avaliação de Professores de Física Através da Teoria dos Construtos Pessoais. Dissertação de Mestrado apresentada ao Programa de Mestrado de Ensino de Ciências da Universidade Federal Rural de Pernambuco, Recife, 2008.

MALDANER, O. A.; ZANON, L. B. Situação de Estudo: uma Organização do Ensino que Extrapola a Formação Disciplinar em Ciências. Espaços da Escola. Ijuí: ano 11, n. 41, p. 45-60, 2001.

MEZZADRA, F.; VELEDA, C.; SÁNCHEZ, M. B. Apostar a la docencia, desafíos y posibilidades para la política educativa argentina. Fundación Cippec. Buenos Aires, ano 2014, 1a ed.

OLIVEIRA, D. A.; MELO, S. D. G. Mudanças no Trabalho e na Luta Docente na Argentina e no Brasil. Revista Adusp, São Paulo, Janeiro, ano 2010.

REIS, J. M. C.; OLIVEIRA, B. R. M.; KIOURANIS, N. M. M. Perspectivas em relação à docência na formação inicial de licenciatura em Química de uma universidade pública. Atas do IX Encontro Nacional de Pesquisa em Educação em Ciências - IX ENPEC, Águas de Lindóia, SP, 2013. 
SANTOS, W. L. P.; SÁ, C. S. S. Licenciatura em Química: carência de professores, condições de trabalho e motivação pela carreira. In: VIII ENPEC - Encontro Nacional de Pesquisa em Educação em Ciências, 2011, Campinas-SP. Anais VIII ENPEC, 2011, p.1-12

SALES, A. C. M.; CHAMON E. M. Q. O. Escolha da Carreira e o Processo de Construção da Identidade Profissional Docente. Educação em Revista, Belo Horizonte, V. 27, n. 03, p. 183m210, dezembro, ano 2011.

SILVA, A. M. Proposta para tornar o Ensino de Química mais atraente. Revista de Química Industrial, Rio de Janeiro, ano 79, n. 731, p. 7-12, 2011.

SILVA, D. N. A desmotivação do professor em sala de aula, nas escolas públicas do município de São José dos Campos-SP. Monografia de conclusão do Curso de Especialização em Gestão Pública Municipal, da Universidade Tecnológica Federal do Paraná, Curitiba, 2012.

SILVA, E. V.; VIANA, K. S. L.; NASCIMENTO, J. C.; JUNIOR, J. V. A. Programa Despertando Vocações para as Licenciaturas: uma proposta piloto extensão internacional. In: $1^{\circ}$ Simpósio Latino americano de Intercambio sobre enseñanza de la Química. La Plata, Buenos Aires, 2014.

TORRICELLI, E. Dificuldades de aprendizagem no Ensino de Química. Tese (Livre Docência). Faculdade de Educação, Universidade Federal de Minas Gerais, Belo Horizonte, ano 2007.

UIS-UNESCO. Compendio Mundial de la Educación. Oportunidades perdidas: El impacto de larepetición y de la salida prematura de la escuela. Montreal: unesco, 2012.

VIANA, M. G.; CESAR, R. C. L. Direito à Educação no Brasil: Exigibilidade Constitucional. Disponível em: $<\underline{\text { http://www.fa7.edu.br/recursos/imagens/File/direito/ic/v encontro/direitoaeducacaonobrasil.p }}$ df> Acesso: 18/09/2015. 